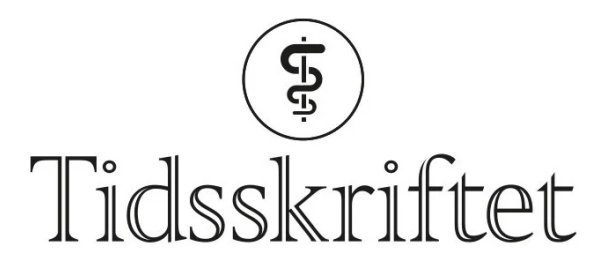

DEN NORSKE LEGEFORENING

\title{
Norge - sjøfartsnasjonen som lar mennesker drukne
}

KRONIKK

JON MAGNUS HAGA

jon.magnus.haga@gmail.com

Jon Magnus Haga er ph.d. og lege. Han er leder av Norsk senter for maritim medisin og dykkemedisin, Yrkesmedisinsk avdeling, Helse Bergen og tidligere avdelingslege i Kystvakten med erfaring fra operasjoner i norske og internasjonale farvann.

Forfatteren har fylt ut ICMJE-skjemaet og oppgir ingen interessekonflikter.

\section{Sjøfolk kommer hverandre til unnsetning. Norge kan ikke lenger lukke øynene for nøden i Middelhavet.}

- Én drukningsulykke er én for mye, sa Erna Solberg, da hun i sommer fikk presentert Redningsselskapets tall over drukningsulykker i Norge (1). Solberg ba «båtfolket» ta ansvar. Det er lett å være enig i en nullvisjon. Ingen fortjener å drukne.

Sommeren 2015 arbeidet jeg som skipslege i Middelhavet, som del av Norges bidrag for å avhjelpe den humanitære situasjonen i havområdene nord for Libya (2). Inntrykkene derfra var sterke. Jeg så skrekkslagne mennesker overlatt til seg selv i åpent hav, tomme for mat og drivstoff og prisgitt vær og vind. Jeg så forkomne mennesker stuvet sammen, tett i tett i gummibåter. Jeg så mennesker nedlåst under dekk, tomme for luft. Jeg så brudd, åpne sår og etseskader. Jeg så skader etter mishandling og vold. Jeg så kropper som fløt i sjøen og mennesker som kjempet for livet i vannmassene. Jeg så voksne og barn. Jeg så gravide og gamle. Jeg så smerte, angst og fortvilelse. Jeg så død.

Omtrent samtidig med at Solberg uttalte sin nullvisjon for Norge, holdt FNs høykommissær for flyktninger (UNHCR) en pressekonferanse på telefon fra Trapani på Sicilia (3). Meldingen var nedslående. Seks år har gått. Nøden i Middelhavet er fortsatt den samme. Håpet om en framtid i Europa tar fortsatt liv i et urovekkende tempo. Og trenden er igjen $\varnothing$ kende. I første halvdel av 2021 fors $\varnothing$ kte over 40 ooo mennesker å krysse Middelhavet (4). Mer enn 1 ooo forsvant i forsøket eller ble funnet omkommet på havet. Det tilsvarer fem menneskeliv hver dag.

\section{Plikt til å hjelpe}


Sjøredning bygger på gjensidighet. Sjøfolk kommer hverandre til unnsetning. Det handler om et skjebnefellesskap og en æreskodeks med tradisjoner århundrer tilbake, første gang nedtegnet som en avtale mellom stater i 1910 (5). Plikten gjelder alle og overalt, og uavhengig av geografi, omstendigheter, nasjonalitet eller fiendskap mellom flaggstater. Mennesket først. Politikk siden.

\section{«Plikten gjelder alle og overalt. Mennesket først. Politikk siden»}

I kjølvannet av forliset til Titanic i 1912 ble skipssikkerhet for alvor satt på dagsordenen. Med den internasjonale konvensjonen om sikkerhet for menneskeliv til sjøs (SOLAS) i 1914, forløperen til dagens konvensjon av 1974, kom krav til skipskonstruksjon, livbåter, redningsvester og radiokommunikasjon (므). I 1979 kom Internasjonal konvensjon om ettersøking og redning til sjøs (SAR-konvensjonen) med detaljerte bestemmelser om organisering av nasjonale søk- og redningsressurser (7.), og senere, i 1982 kom FNs havrettskonvensjon, kjernen i det vi ofte omtaler som havretten, og stadfestet en tydelig ansvarsfordeling for søk og redning mellom kyststat, flaggstat og skipsfører (묘). Ansvar for organisering skulle påhvile kyststat. Ansvar for tilsyn skulle påhvile flaggstat. Plikt til å hjelpe skulle gjelde alle som ferdes på sjøen.

\section{Europas svar på flyktningkrisen}

Krisen i det sentrale Middelhavet er ikke nyoppstått. Den utviklet seg som en etterdønning etter den arabiske våren i 2011. I Europa fikk krisen først særlig oppmerksomhet i oktober i 2013, da en fiskebåt fra Libya fullastet med migranter havarerte utenfor den sørlige italienske ferieøya Lampedusa. Kloss inntil land, for øynene til forferdete badegjester på en populær strand sør på øya, kantret fiskebåten og dro med seg over zoo migranter i døden. Bildene sjokkerte et helt Europa.

Noe måtte gjøres. Etter kort tid lanserte italienske myndigheter operasjon Mare nostrum (9.). Italia skulle aktivt søke etter migranter i havområdene utenfor Libya og komme dem til unnsetning. Operasjonen disponerte betydelige militære ressurser, inkludert flere skip, ubåter og fly. Operasjonen viste seg snart å bli svært kostbar for Italia å bære alene og ble avsluttet allerede etter ett år. Til erstatning etablerte EU operasjon Triton (fra

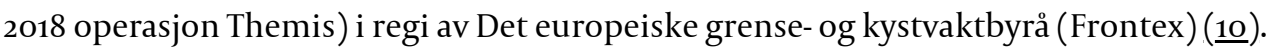
Totalt 28 land deltok i operasjonen, deriblant Norge. Triton fikk et sammensatt oppdrag, inkludert grensekontroll og etterforskning av kriminelle nettverk. Søk og redning ble ikke formelt lagt inn som en del av oppdraget, utover de generelle forpliktelsene som påhviler enhver skipsfører etter havretten. Norge støttet Triton med personell fra politiet og Forsvaret og fartøyene Siem Pilot og Olympic Commander. I perioden 2015-17 bidro Norge til å redde om lag 30 ooo menneskeliv i Middelhavet.

Avviklingen av Mare nostrum i 2014 svekket redningskapasiteten i det sentrale Middelhavet betraktelig. Triton disponerte færre ressurser enn sin forløper, oppgavene var flere og operasjonsområdet mer tilbaketrukket. Tomrommet som oppstod, ble fylt av ideelle aktører. Leger uten grenser, SOS Mediterranée, Sea Watch, Migrant Offshore Aid Station med flere etablerte egne redningskapasiteter i Middelhavet. Organisasjonene bidro til å dekke opp for manglende politisk vilje til søk og redning hos europeiske myndigheter. Hjelpearbeiderne ble hyllet som helter.

Vinden skulle snart snu. I takt med økende migrasjonsstrømmer over Middelhavet bredte det seg skepsis og mistenksomhet i Europa. Det kom forestillinger om at sjøredning bidro til økt migrasjon. Det ble påstått at flertallet av migrantene var lykkejegere uten behov for beskyttelse. Det ble sagt at migrantene kunne hjelpes der de var, og det ble advart mot 
«svenske tilstander». Sosiale medier ble brukt aktivt for å spre dårlig dokumenterte påstander. En polarisering ble ødeleggende for debatten. Hjelpearbeidere som i 2015 ble hyllet for sin innsats, møtte anklager om medansvar for nød og for menneskesmugling(1ㅡ).

\section{"Ingen kan leve med usikkerhet omkring hvorvidt europeiske myndigheter aktivt motarbeider humanitet og bevisst lar mennesker drukne»}

Endrede politiske forutsetninger i Europa resulterte i en gradvis reduksjon i redningskapasitetene i Frontex. Økt fokus ble lagt på grensekontroll og kriminalitetsbekjempelse. Forslag om styrking av redningskapasiteter i Frontex, fremmet i

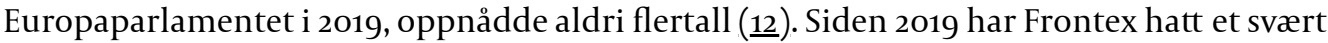
beskjedent fotavtrykk i Middelhavet (13). Kapasitet til redning på sjøen har i stor grad blitt erstattet av kapasiteter til overvåkning fra luften. De humanitære organisasjonene har fått et stadig større tomrom å fylle.

\section{Et folkerettslig skråplan}

Parallelt med redusert tilstedeværelse av Frontex i Middelhavet inngikk EU i 2017 en avtale med Libya om støtte til opprustning av landets søk- og redningskapasiteter (14.). Norge bidro gjennom EUs flergiverfond for stabilitet og tiltak mot irregulær migrasjon i Afrika (EUTF). Pengene gikk blant annet til styrking av den libyske kystvakten. Italia signerte i tillegg et eget omforent memorandum med Libya (15) og ga økonomisk støtte direkte til innenriksdepartementet, med ansvar blant annet for interneringsleirer for flyktninger $\mathrm{i}$ Libya. Avtalene høstet hard kritikk hos menneskerettighetsorganisasjoner (16,17.). Det forelå allerede på dette tidspunktet dokumentasjon av umenneskelige forhold for migranter i Libya, inkludert tortur, misbruk, slavearbeid og menneskehandel.

Oppbyggingen av den libyske kystvakten gjorde at situasjonen gikk fra vond til verre (표). Det kom rapporter om hensynsløs behandling av migranter på sjøen og om skjødesløse redningsoperasjoner der migranter ble utsatt for unødig risiko. Det kom også rapporter om skarpe skudd rettet både mot migranter og mot humanitære hjelpearbeidere, voldelige avstraffelser av migranter, om korrupsjon og om utilbørlig samarbeid mellom libysk kystvakt og menneskehandlere.

Europas støtte til oppbygging av den libyske kystvakten er et tvilsomt skråplan. Både Flyktningkonvensjonen og Den europeiske menneskerettighetskonvensjonen har forbud mot kollektive utvisninger og mot retur av mennesker til land der de risikerer forfølgelse prinsippet om såkalt non-refoulement (19.). Europeiske myndigheter kan hverken ilandføre migranter i Libya eller taue gummibåtene deres tilbake til libysk farvann, såkalte pushbacks, uten at det er et brudd på menneskerettighetene. Det er også et brudd på havretten. Skipbrudne skal tas med til trygg havn. Libya er ikke trygt. Italia er tidligere dømt i Den europeiske menneskerettighetsdomstolen for retur av migranter til Libya og for lidelsene det medførte for migrantene (으). Ingen europeiske myndigheter returnerer lenger mennesker til Libya. Men returene har ikke stoppet opp. Den libyske kystvakten har tatt over, finansiert av Europa. Med vår støtte blir mennesker på flukt kollektivt returnert til Libya, holdt fanget under umenneskelige forhold og effektivt avskåret fra å søke om beskyttelse i Europa. Libya utfører en jobb som Europa ikke lovlig kan utføre selv. Vi beveger oss på et farlig skråplan som fører bort fra våre humanistiske idealer. Strategien er i beste fall uforsvarlig, i verste fall kriminell. Amnesty International er tydelig i sin

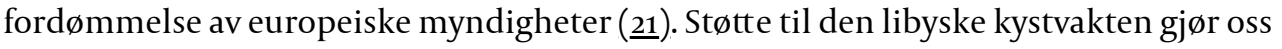
medskyldige i overgrepene migrantene utsettes for.

\section{Kriminalisering av humanitet}


Samarbeidet mellom europeiske myndigheter og humanitære organisasjoner har tidvis vært anstrengt. Organisasjoner har rapportert om situasjoner med juridiske hindringer, politisk press og unnlatelser (22). Redningsfartøy har blitt nektet anløp til havner, blitt avregistrert eller holdt tilbake etter havnestatskontroller. Informasjon om havsnød fra overvåkningsfly har blitt formidlet selektivt til libysk kystvakt og tilbakeholdt fra humanitære organisasjoner. Covid-19 har blitt brukt som påskudd for å erklære havner i Italia og Malta som ikke trygge etter havretten og dermed uegnet for ilandføring av migranter.

\section{«Solberg ba 'båtfolket’ om å ta ansvar.Jeg vil be statsministeren om å gjøre det samme»}

Den europeiske unions byrå for grunnleggende rettigheter (FRA) har siden 2016 ført oversikt over juridiske prosesser innledet mot humanitære organisasjoner i Middelhavet (23). Listen er lang og øker stadig. Den inkluderer alt fra tekniske forhold ved fartøy til påstått ulovlige handlinger utført av enkeltpersoner. Flere av sakene har medført arrest i fartøy, bøter eller fengsel. I 2018 måtte Leger uten grenser og SOS Méditerranée ta sitt fartøy Aquarius permanent ut av operasjon etter å ha bli utsatt for flere omstridte søksmål.

Kriminalisering har bidratt til å svekke en hardt prøvd redningskapasitet. I sommer var kun ett av seks humanitære redningsfartøy i operasjon i Middelhavet. Resten var holdt tilbake administrativt i europeiske havner. Også i saker der tiltale ble frafalt, medførte de rettslige prosessene langvarige avbrudd i tilgjengelighet av redningskapasitet. Det rettes nå alvorlige anklager mot europeiske myndigheter om en bakenforliggende politisk agenda (24). . Disse anklagene må undersøkes. Ingen kan leve med usikkerhet omkring hvorvidt europeiske myndigheter aktivt motarbeider humanitet og bevisst lar mennesker drukne.

To av de humanitære redningsskipene i Middelhavet seiler under norsk flagg (Geo Barents og Ocean Viking). Det påhviler Norge et særlig ansvar å følge med på disse i tiden framover.

\section{En nullvisjon må gjelde alle}

Én drukningsulykke er én for mye. Solberg ba «båtfolket» om å ta ansvar. Jeg vil be statsministeren om å gjøre det samme. Organisering av søk og redning er et statlig ansvar etter havretten. Dagens strategi i Middelhavet har spilt fallitt. FNs høykommissær for menneskerettigheter var nylig krystallklar i sine konklusjoner (25). Europas tilnærming til krisen er ikke egnet til å fremme hverken liv eller helse. Snarere enn å avhjelpe situasjonen legger den til rette for overgrep mot sårbare mennesker.

Solberg leder en betydelig sjøfartsnasjon med stolte tradisjoner. Hun leder et internasjonalt høynivåpanel for bærekraftig havøkonomi. Hun er ambassadør for prosjektet One Ocean Expedition, en jordomseiling for maritim bærekraft i regi av Stiftelsen Statsraad Lehmkuhl, Helse Bergen og en rekke andre ideelle, offentlige og private aktører. Bærekraft handler om mennesker. Jeg håper Solberg ser sammenhengen. Jeg håper vår neste regjering ser sammenhengen. Og kjenner sin besøkelsestid.

Vi er en nasjon av sjøfolk. Vi må finne tilbake til vårt moralske kompass. Vi må heie fram humanitet og stå opp for havretten og asylinstituttet.

Ingen fortjener å drukne. En nullvisjon må gjelde alle.

\section{LITTERATUR}

1. NRK. Solberg ber båtfolket ta ansvar. https://www.nrk.no/nyheter/solberg-ber-batfolket-ta-ansvar1.15562129 Lest 3.8.2021. 
2. Haga JM. Sjøveien til Europa - en våt massakre. Tidsskr Nor Legeforen 2015; 135: 1868-9. [PubMed] [CrossRef]

3. FNs høykommissær for flyktninger. UNHCR warns of mounting refugee and migrant deaths in the Central Mediterranean. https://www.unhcr.org/news/briefing/2021/5/6o9134f74/unhcr-warnsmounting-refugee-migrant-deaths-central-mediterranean.html Lest 3.8.2021.

4. Europe Situations. Data and Trends - Arrivals and Displaced Populations (June 2021). Genève: FNs høykommissær for flyktninger, 2021. https://data2.unhcr.org/en/documents/details/87888 Lest 3.8.2021

5. Convention for the Unification of Certain Rules of Law respecting Assistance and Salvage at Sea. Brüssel: 1910. http://www.admiraltylawguide.com/conven/salvage1910.html Lest 3.8.2021.

6. International Convention for the Safety of Life at Sea (SOLAS). London: Den internasjonale sjøfartsorganisasjonen, 1974. https://treaties.un.org/doc/Publication/UNTS/Volume\%201184/volume1184-I-18961-English.pdf Lest 3.8.2021.

7. International Convention on Maritime Search and Rescue (SAR). London: Den internasjonale sjøfartsorganisasjonen, 1979. https://treaties.un.org/doc/Publication/UNTS/Volume\%201405/volume1405-I-23489-English.pdf Lest 3.8.2021.

8. United Nations convention on law of the sea (UNCLOS). New York: De forente nasjoner, 1982. https://www.un.org/depts/los/convention_agreements/texts/unclos/unclos_e.pdf Lest 3.8.2021.

9. Musarò P. Mare Nostrum: the visual politics of a military-humanitarian operation in the Mediterranean Sea. Media Cult Soc 2017; 39: 11-28. [CrossRef]

10. Europakommisjonen. Frontex Joint Operation 'Triton' - Concerted Efforts to Manage Migration in the Central Mediterranean. https://ec.europa.eu/commission/presscorner/detail/en/MEMO_14_566 Lest 3.8.2021.

11. Cusumano E, Villa M. From "angels" to "vice smugglers": the criminalization of sea rescue NGOs in Italy. Eur J Crim Policy Res 2021; 27: 23-40. [CrossRef]

12. Europaparlamentet. 2019/2755(RSP) Search and rescue in the Mediterranean (SAR) (Procedure rejected). https://oeil.secure.europarl.europa.eu/oeil/popups/ficheprocedure.do? lang=en\&reference $=2019 / 2755$ (RSP) Lest 3.8.2021.

13. Radjenovic A. Briefing: Search and rescue in the Mediterranean. Brüssel: European Parliament, 2021.

https://www.europarl.europa.eu/RegData/etudes/BRIE/2021/659442/EPRS_BRI(2021)659442_EN.pdf Lest 3.8.2021.

14. Joint Communication of the European Commission to the European Parliament. European Council and the Council on Migration on the Central Mediterranean route - Managing flows, saving lives. Brüssel: Europakommisjonen, 2021. https://ec.europa.eu/home-affairs/sites/default/files/whatwe-do/policies/european-agenda-migration/proposal-implementation-

package/docs/20170125_migration_on_the_central_mediterranean_route__managing_flows_saving_lives_en.pdf Lest 3.8.2021.

15. Palm A. The Italy-Libya Memorandum of Understanding: The Baseline of a Policy Approach Aimed at Closing All Doors to Europe? EU Immigration and Asylum Law and Policy 2017.

https://eumigrationlawblog.eu/the-italy-libya-memorandum-of-understanding-the-baseline-of-apolicy-approach-aimed-at-closing-all-doors-to-europe/ Lest 3.8.2021.

16. A Perfect Storm: The Failure of European Policies in the Central Mediterranean London: Amnesty International, 2017. https://www.amnesty.org/en/wpcontent/uploads/2021/05/EURo366552017ENGLISH.pdf Lest 3.8.2021.

17. NGOs Joint Statement. EU: Time to review and remedy cooperation policies facilitating abuse of refugees and migrants in Libya. London: Amnesty International, the Italian Recreational and Cultural Association (ARCI), Association for Juridical Studies on Immigration (ASGI), Avocats Sans Frontières (ASF), Cairo Institute for Human Rights Studies (CIHRS), Euro-Mediterranean Human Rights Network (EuroMed Rights), the Global Legal Action Network (GLAN), Human Rights Watch (HRW), International Federation for Human Rights (FIDH), Lawyers for Justice in Libya (LFJL), Oxfam International og Saferworld, 2020. https://www.amnesty.org/en/wpcontent/uploads/2021/05/EUR0122172020ENGLISH.pdf Lest 3.8.2021.

18. Leger uten grenser. MSF accuses Libyan coastguard of endangering people's lives during Mediterranean rescue. https://www.msf.org/msf-accuses-libyan-coastguard-endangeringpeople\%E2\%80\%99s-lives-during-mediterranean-rescue Lest 3.8.2021.

19. FNs høykommissær for flyktninger. General legal considerations: search-and-rescue operations involving refugees and migrants at sea. https://www.refworld.org/docid/5azegefd4.html Lest 3.8.2021.

20. Case of Hirsi Jamaa and others v. Italy (application no. 27765/o9). Strasbourg: Den europeiske menneskerettsdomstol, 2012. http://hudoc.echr.coe.int/eng?i=o01-109231 Lest 3.8.2021. 
21. Amnesty International. Libya: European governments complicit in horrific abuse of refugees and migrants. https://www.amnesty.org/en/latest/news/2017/12/libya-european-governments-complicit-inhorrific-abuse-of-refugees-and-migrants/ Lest 3.8.2021.

22. Leger uten grenser. In the first 6 months of 2021, more than 1,140 people have died trying to cross the Mediterranean. https://www.msf.org/mediterranean-migration-depth Lest 3.8.2021.

23. Den europeiske unions byrå for grunnleggende rettigheter. June 2021 Update - Search and Rescue (SAR) operations in the Mediterranean and fundamental rights.

https://fra.europa.eu/en/publication/2021/june-2021-update-ngo-ships-sar-activities Lest 3.8.2021.

24. Leger uten grenser. MSF is determined to return to sea to save lives after Geo Barents detained in Italy. https://www.msf.org/msf-determined-return-sea-save-lives-after-geo-barents-detained-italy Lest 3.8.2021.

25. "Lethal Disregard": Search and rescue and the protection of migrants in the central Mediterranean Sea. New York, NY: FNs høykommissær for menneskerettigheter, 2021. https://www.ohchr.org/Documents/Issues/Migration/OHCHR-thematic-report-SAR-protection-atsea.pdf Lest 3.8.2021.

Publisert: 20. august 2021. Tidsskr Nor Legeforen. DOI: 10.4045/tidsskr.21.0568 Mottatt 4.8.2021, godkjent 15.8.2021.

(C) Tidsskrift for Den norske legeforening 2023. Lastet ned fra tidsskriftet.no 26. april 2023. 